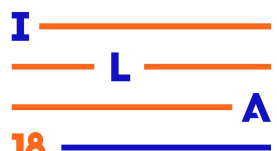

\title{
DESIGN DE INTERAÇÃO: UMA SINCRONIA DE ELEMENTOS DE DESIGN, JOGOS E DESENVOLVIMENTO INFANTIL.
}

\section{DESIGN OF INTERACTION: a synchrony of design elements, digital games and child development.}

\author{
Anelise Thaler ${ }^{1}$, M.Sc. \\ Francisco Antonio Pereira Fialho ${ }^{2}$, D.Sc. \\ Universidade Federal de Santa Catarina \\ e-mail: anethaler@gmail.com \\ Universidade Federal de Santa Catarina \\ e-mail: fapfialho@gmail.com
}

\begin{abstract}
Estamos na era dos nativos digitais, nessa era, as crianças têm habilidades e facilidades esplêndidas na interação com o meio digital. Assim, há uma percepção nítida no sentido "que precisamos maximizar o tempo que as crianças usam a tecnologia de modo que realmente atenda suas necessidades quanto ao desenvolvimento cognitivo, emocional e intelectual" (WARREN, 2015). Nesse contexto, o presente artigo tem como objetivo apresentar a perspectiva e entendimento de três áreas, desenvolvimento na infância, design de interação e jogos digitais. Realizando uma pesquisa exploratória, o trabalho resulta em uma expectativa aprimorada de ideias e descoberta dos aspectos relativos ao fato estudado. Assim, nas considerações serão apresentados os padrões de design de interação que orientem a criança em uma experiência lúdica e a essencial sincronia de elementos de design, jogos digitais e desenvolvimento infantil.
\end{abstract}

Palavras Chaves: desenvolvimento na infância, design de interação e jogos digitais.

Abstract

We are in the era of digital natives, in this era, children have splendid abilities and facilities in the interaction with the digital medium. Thus, there is a clear perception that "we need to maximize the time children use technology to truly meet their cognitive, emotional, and intellectual development needs" (Warren, 2015). In this context, the present article aims to present the perspective and understanding of three areas, development in childhood, interaction design and digital games. By conducting an exploratory research, the work results in an improved expectation of ideas and discovery of aspects related to the fact studied. Thus, in the considerations will be presented the patterns of interaction design that guide the child in a playful experience and the essential synchrony of design elements, digital games and child development.

Key words: development in childhood, interaction design and digital games.

\section{Introdução}

As crianças aprendem naturalmente através do brincar. Elas absorvem e processam todas as novas informações sobre esse novo mundo em que chegaram com todos os seus sentidos. É assim que se relacionam com novos conceitos e os tornam tangíveis.

$\mathrm{Na}$ última década, os produtores de jogos digitais têm evoluído consideravelmente na produção dos jogos. Dessa maneira, os jogos digitais, simuladores vêm ganhando seu espaço. 


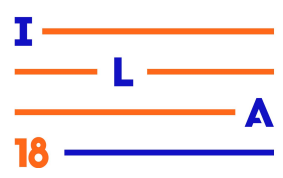

Segundo Presnsky (2010, p. 3): "os videogames têm um enorme potencial que os livros e, depois os computadores tiveram [...]. A diferença entre livros e jogos eletrônicos é o fato de a capacidade dos games em proporcionar coisas boas ter sido completamente negligenciada pela maioria das pessoas".

Os jogos digitais têm um enorme potencial, na década atual, seu cenário vem mudando, onde se tem observado a tendência para um olhar menos nocivo. Com isso, vem apresentando um propósito, revolucionário para o bem.

Há uma combinação de materiais, presente nos jogos digitais (multimídia, figuras, sons e animações), os quais são uma sincronia de história, arte, tecnologia e experiência para o usuário. A partir do momento que estes elementos entram em sincronia com a cultura, teremos um design de experiência que afetará os acontecimentos constitutivos do ser.

Para os nativos digitais a construção do ser, pode ser diferente. "Os nativos digitais são muito diferentes de quando éramos crianças, eles estão mudando constantemente em termos de comportamento, necessidades e expectativas" (WARREN, 2015 p. 420).

Por conta destas mudanças, o design de jogos é uma maneira para potencializar os conteúdos lúdicos e lúcidos que cative mais adeptos, a provar novas experiências digitais.

"O design de jogos não é apenas um ofício tecnológico. É a maneira do século XXI pensar e liderar. E jogar não é apenas um passatempo. É a maneira do século XXI de trabalhar em grupo para conquistar uma mudança real" (MCGONIGAL, 2017, p. 312).

Há uma quantidade enorme de experiência do usuário que podem ser aprendidas no mundo do design de jogos: orientar o comportamento humano, ensinar novos conceitos, contar histórias e comunicação, além da satisfação que os humanos encontram no domínio progressivo.

\section{Desenvolvimento humano na infância}

O desenvolvimento humano está condicionado a influências do ambiente e também na hereditariedade, sendo que esses tipos de influências fazem parte da diferenciação pessoal.

Para entender semelhanças e diferenças no desenvolvimento, é preciso observar dois tipos de influências normativas: eventos biológicos e ambientais (PAPALIA e FELDMAN, 2013).

De acordo com entendimento de Lèvy (1999), toda e qualquer reflexão sobre o devir dos sistemas de educação e formação na cibercultura, deve amparar-se numa análise anterior da mutação atualizada da relação com o saber, pois, as tecnologias intelectuais suportadas pelo ciberespaço ampliam, exteriorizam e alteram funções cognitivas humanas, tais como memória, imaginação, percepção e raciocínio, além de favorecer novas maneiras de acesso à informação.

Alguns estudos interculturais sustentam uma progressão do pensamento rígido e ilógico de crianças mais jovens, para o pensamento flexível e lógico de crianças com mais idade.

Piaget entendia que tal mudança está condicionada a maturação neurológica e adaptação ao ambiente e que não está atrelada à experiência cultural (PAPALIA e FELDMAN, 2013).

Conforme exposto por Warren (2015, p. 526-576), entender como a teoria do desenvolvimento cognitivo de Jean Piaget, ajuda a ilustrar as habilidades cognitivas de crianças de diferentes idades. Assim, no desenvolvimento de jogos é necessário entender os quatro conceitos que suportam esta teoria, tal como apresentados a seguir:

- Esquemas: comportamentos que identificam os objetos e suas finalidades.

- Assimilação: identificação de objetos com base em seus atributos físicos.

- Acomodação: classificação de objetos com base em vários atributos.

- Equilíbrio: o equilíbrio entre assimilação e acomodação.

Ao projetar para crianças, além de olhar para o 


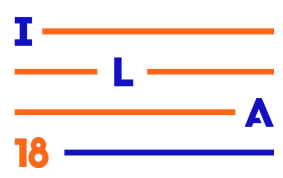

desenvolvimento cognitivo, devemos olhar também para o emocional, físico e tecnológico.

Conforme a criança vivencia experiências, e, seus esquemas vão progredindo no desenvolvimento de sucção, cair, bater e assim por diante, sua compreensão e classificação de objetos que compõem o seu mundo irá naturalmente expandir.

Para melhor entendimento, Warren (2015, p. 576-586), descreve os seguintes estágios do desenvolvimento infantil.

- Sensório-motor: 0-2 anos a criança começa a descobrir os objetos que compõem o mundo.

- Pré-motor sensório-motor: 2-6 anos as crianças são egocêntricas e apenas aprendem e compreendem os conceitos e objetos, como se relacionam com eles.

- Operações concretas: $7-11$ as crianças começam a usar a lógica indutiva e resolver problemas.

- Operações formais: 12 anos ou mais, as crianças começam a usar resumo e pensamentos, raciocínio dedutivo para obter conhecimento.

Em um ambiente virtual, temos a oportunidade de desenvolver esquemas digitais, de modo infantil, criando elementos para interagir clicando, arrastando, batendo ou agitando. Este comportamento ajudará a criança a aprender os gestos e as interações que irão realizar no futuro.

Por exemplo, nas brincadeiras de faz-de-conta a criança está aprendendo a lidar com o mundo exterior, e isso é absolutamente crucial para o desenvolvimento na infância por diversos aspectos.

A criança desenvolve as habilidades sociais e emocionais, brinca de médico, ao medir a temperatura, está refinando suas habilidades sociais, bem como começam a entender como se comportar em situações do mundo real.

O desenvolvimento de outras emoções, tais como empatia e gentileza, também entra em jogo quando as crianças avaliam as condições e entendem qual a melhor forma de tratá-la.

Assim, os jogos e a brincadeiras oferecem um conjunto contínuo de ferramentas de aprendizado que envolvem a curiosidade natural de todas as crianças e os ajuda a desenvolver as habilidades e a confiança de que precisarão no futuro. "As crianças aprendem mais coisas positivas, úteis para seu futuro, com os games do que na escola!" (PRENSKY, 2010 p. 28).

As crianças, nos últimos tempos, vêm fascinando-se com jogos digitais e passam bastante tempo em frente a tela de computador. De acordo com apontamento de Santaella (2003), quaisquer meios de comunicação ou mídia são inseparáveis das formas de socialização e cultura que são capazes de criar, de maneira que o advento de cada novo meio de comunicação traz um ciclo cultural que lhe é próprio.

Assim, esses novos meios podem produzir mudanças no desenvolvimento neurológico e cultural das crianças. No período de desenvolvimento e aprendizagem da criança, o jogo estimula seu cérebro e, com uma pequena ajuda, eles podem prosperar no sentido do ser.

Dentro desse entendimento geral, se verifica que diversos autores argumentam que as habilidades e aprendizagens acontecem independentemente do tipo de jogo. A aprendizagem pode surgir em muitos momentos da vida, em outras vezes pela experiência mencionada por um indivíduo sobre um determinado assunto, pelo convívio na sociedade, na escola, no trabalho, entre outros.

\section{Design de Interação / UX}

O design de interação é uma abordagem do design dedicada a projetar comportamento dos artefatos interativos. Segundo Saffer (2015, p.3) "design de interação refere-se ao comportamento e comportamento é muito mais difícil de observar que aparências".

O design de interação é a concepção de produtos e serviços interativos, particularmente a forma como 


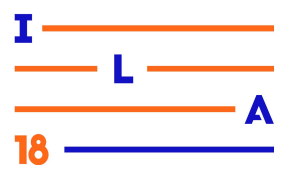

as pessoas interagem com os produtos e serviços. É a área do design especializada no projeto de interface, dispositivos interativos, jogos digitais entre outros. Tem como intenção o uso das mídias digitais como meio de comunicação entre as pessoas. Assim classifica-se como uma atividade multidisciplinar, cabendo ao designer de interação abordar a atuação do usuário final em seus aspectos sociais, culturais e econômicos.

Bill Verplank (2007) define design de interação como design para pessoas. Para ele o design de interação precisa responder a três questões: (i) Como as pessoas agem? Através de affordances, propriedades percebidas e reais de um objeto, principalmente que fornecem indicações de operação, maneira como as pessoas agem, manipulam e manuseiam apenas ao olhar ; (ii) Como elas se sentem? Mostrar o efeito de uma ação, com os feedbacks, muitas das emoções vem da qualidade sensorial do meios comunicação com uma máquina ou sistema; e (iii) Como elas entendem? O que envolve o modelo mental de como saber o que fazer apresentando uma visão geral de como se dá o funcionamento de objetos ou sistemas.

$\mathrm{O}$ ato de observar como as pessoas interagem com artefatos é uma ótima maneira de identificar padrões, objetivos e valores, e assim obter insights. No design este ato é chamado de necessidade.

"Design de interação é por sua natureza contextual: resolve problemas específicos sob um determinado conjunto de circunstâncias, usando os materiais disponíveis" (SAFFER, 2015, p. 4).

Eles têm muito mais em comum do que a distinção percebida geralmente sugere, e os profissionais da experiência do usuário podem obter enormes benefícios explorando as soluções que os jogos encontraram para os problemas reais do design. Tem sido difícil encontrar recursos que realmente conectem os mundos de UX e design de jogos.

\subsection{Padrões e Fenômenos}

No campo, as principais coisas que um designer procura são padrões e fenômenos únicos. Os padrões podem ser definidos como: padrões de comportamento, padrões em histórias, padrões de respostas a uma pergunta - qualquer ação ou ideia que se mantenha recorrente.

As regras são: (1) Veja ou ouça uma vez, é um fenômeno. Anotá-la (2) veja ou ouça duas vezes, é uma coincidência ou um padrão emergente. Anotá-la. (3) veja ou ouça três vezes, é um padrão. Anotá-la. (SAFFER, 2015).

Por vezes, os padrões não surgirão até que os dados da pesquisa tenham sido analisados, às vezes, um padrão é óbvio no meio de fazer a pesquisa. De fato, uma boa regra de ouro é que, quando você começa a perceber muitos padrões, provavelmente fez pesquisas suficientes para tirar conclusões significativas.

A prática do design de interação, tem um conjunto de condições a reconsiderar como noções de especificações antes de construir. O Projeto envolve pensar através de esboços e outras representações tangíveis. Para design de interação, existem implicações específicas a serem observadas a partir da natureza temporal e contextual.

\subsection{Diferenças ao projetar para crianças:}

Como designer não devemos ver o que é ser criança, mas internalizar como projetar para suas necessidades específicas, seja cognitiva, física, social e emocional.

Projetar para as crianças é diferente de projetar para adultos. Segundo Warren (2015 p. 366), "projetar para os adultos o objetivo é chegar ao final. Para as crianças a chegada é apenas uma parte da história". Em seu livro "Design For Kids", esse autor apresenta as diferenças que devem ser consideradas:

- Conflito/Desafio: os conflitos/desafios são importantes para os adultos, mas em nível macro. Eles ajudam a mover a história ao longo do jogo. Mas para as crianças a resolução de micro conflitos/desafios é importante, pois representa na vida real o entendimento para resolver seus próprios conflitos interiores.

- Feedback: Ao contrário dos adultos, crianças adoram feedback visual e auditivo 


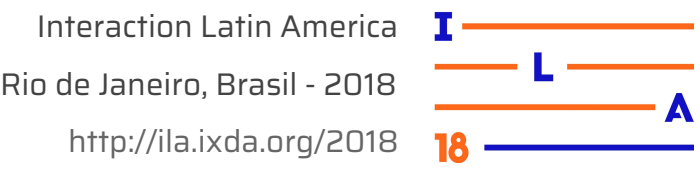

quando realizam uma ação no espaço digital. Cada interação, tem a necessidade de produzir algum tipo de resposta ou reação. Elas gostam de ser recompensadas por tudo o que fazem.

- Confiança: As crianças sentem-se mais confiantes em relação aos adultos, isso ocorre devido a sua incapacidade antecipar as ramificações de suas ações.

- Mudança: Como sabemos as crianças são seres em mutação, diferente dos adultos, por isso, é importante entender as diferenças de idade e as implicações que elas representam ao projeto. Os níveis de acesso às atividades e conteúdos devem ser apropriados para eles.

Diante das diferenças apontadas, os designers de interação moldam um material bruto, produzido por engenheiros e programadores em produtos, tecnologias digitais em produtos, que as pessoas gostem de usar, que sejam úteis e agradáveis, que atenda as necessidades dos usuários.

\subsection{Semelhanças ao projetar para adultos $e$ crianças}

$\mathrm{O}$ design atende às demandas dos usuários, acolhendo suas necessidades e desejos, por meio de produtos e sistemas, que facilitem a sua vida cotidiana. Entretanto, existem semelhanças e diferenças ao projetar para determinados públicos.

Dessa forma, Warren (2015 p. 376) aborda as semelhanças de projeto, que são:

- Consistência: A consistência no projeto de um site, app ou jogo, está a certificação dos padrões de design, tanto adultos quanto crianças, se irritam com elementos aleatórios e desnecessários. Um princípio relevante é manter a interação e feedbacks consistentes para que os usuários sejam capazes de aprender as funcionalidades.

- Finalidade: tanto as crianças quanto os adultos precisam ser envolvidos rapidamente nos objetivos e finalidades do jogo. Por exemplo, o jogo deve ser divertido.

- Surpresa: Ambas, crianças e adultos, desenvolvem expectativas em torno de como se comporta o jogo. Gostam de ter interações, expectativas já conhecidas. Nem crianças e nem adultos estão interessados em ser surpreendidos com experiências diferente das esperadas.

O designer precisará fazer um esforço conscientemente para entender qual o grau cognitivo, físico e emocional dos usuários, certificando-se de que seu projeto foi mapeado adequadamente (WARREN, 2015 p. 412).

Para isso, terá que ter entendimento do processo de criação de um projeto, atentando-se às expectativas do usuário, seja elas cognitivas, físicas, social ou emocional.

Para (Warren, 2015 p. 420), o processo "4As" para desenvolvimento de design para crianças tem a seguinte estrutura:

- Absorb / Absorver - Nesta parte é necessário passar um bom tempo assistindo e absorvendo como as crianças interagem, como jogam, como se comunicam, como manipulam os objetos, como interagem com as outras crianças e com os itens do ambiente.

A pesquisa observacional requer brinquedos e jogos apropriados para a idade. Absorver como as crianças se aproximam nas atividades de construção colaborativa. Observar o que eles escolhem para brincar, quanto tempo para escolher com o que vai brincar, quanto tempo brinca e quando decidem brincar com outra coisa, os diferentes comportamentos.

Por exemplo, os meninos interagem com carros, colocando-os em linha reta, correndo em rampas, fazendo-os voar. Já as meninas gostam de atribuir personalidade aos veículos (carros) como fariam com os bonecos ou animais. Crianças mais novas preferem brincar com objetos físicos.

Esse comportamento ocorre porque elas estão 
tentando descobrir como eles se encaixam no mundo ao seu redor, quando as crianças associam aos objetos oferecidos um comportamento não tradicional, significa que o jogo deve focar-se em coisa legais que as elas podem fazer. Por esse motivo, você deve se concentrar nos atributos exclusivos dos próprios objetos (WARREN p.457).

- Análise - Fazer o fluxo, agrupamento e categorias das atividades para identificar os padrões e direção geral para o projeto que quer criar. Por outro lado, pode focar no fluxo de interações individuais anotando padrões e tendências para descobrir o que olhar e como olhar pode funcionar.

- Arquitect - Arquitetar: Criar uma estrutura do seu jogo do que estiver criando, as funções do sistema.

- Assess - Avaliar - Obter um protótipo e avaliar com as crianças. Pedir para completar a tarefa específica, ou pedir para brincar e observar como eles interagem. É importante que os pais também sejam avaliados nesta fase. As crianças testam, e os pais aprovam. "Não depende das crianças e sim dos pais".

Explicar o conceito do projeto e deixar as crianças participarem do projetar, é uma técnica que auxilia ao compreender que tipos de interações eles esperam, esse processo ajudará a entender melhor as habilidades cognitivas dos usuários e as expectativas sobre o conteúdo e o fluxo que deve seguir.

"O desenvolvimento de novos produtos é uma atividade complexa, ela requer pesquisa, planejamento cuidadoso, controle meticuloso e o mais importante, métodos sistemáticos" (BAXTER, 2000 p. 33).

Desenvolver jogos digitais fáceis de aprender, eficazes e que proporcionam experiência agradável ao usuário faz parte do design de interação. Ao conhecer uma realidade, logo é possível traduzir modos de ser e de fazer, por meio de processos criativos próprios ou pela aplicação de técnicas já instituídas culturalmente.

O conhecimento dá ao designer autonomia e independência de ação. $\mathrm{O}$ ato de conhecer é natural e dá-se por meio da observação, da assimilação, pelos sentimentos e motivações num processo dinâmico que é desenvolvido de maneira formal e informal. Ao conhecer, desvela-se a realidade e a possibilidade de ação e de controle sobre essa mesma realidade.

\section{Jogos Digitais}

Os jogos na realidade desempenham um papel fundamental na cultura humana, vis a vis a participação do faturamento do setor que depois da indústria do petróleo e automotiva, é a que mais fatura no mundo. (SANTAELLA, 2004).

No entanto, existem várias críticas relacionadas ao caráter nocivo destes jogos, principalmente relacionadas a violência e agressividade.

Porém, os jogos não resultam em comportamentos agressivos, mas propiciam elaboração dos aspectos subjetivos, à medida que se constituem em espaços de catarse, nos quais as pessoas podem resignificar seus medos e desejos (ALVES, 2009).

Outro aspecto interessante a se comentar sobre os jogos, refere-se a sua interdisciplinaridade. Os games são híbridos, porque envolve programação, roteiro de navegação, design de interface, técnicas de animação e usabilidade.

Esta hibridização é resultado da natureza intersemiótica da linguagem dos games. Outra característica interessante dos games que tem inserção na cultura é a imersão e interatividade. A interatividade é uma atividade intrínseca da comunicação digital (SANTAELLA, 2004).

Outro ponto importante é a narrativa dos games, que também faz parte deste arcabouço cultural particular. Ela utiliza ficções hipertextuais como a própria narrativa do jogo em si. Santaella (2004) também coloca as comunidades virtuais como parte desta cultura dos games. Existe, segundo a autora, o chamado ecossistema de subculturas, ou seja, mega comunidades como a America on Line ou Microsoft e dentro delas, micro comunidades, cada uma com suas especificidades. 


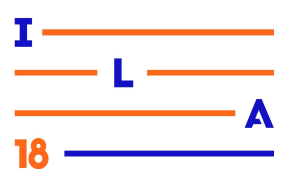

Analisando todos estes aspectos, concluímos que a cultura dos games é extremamente rica, justificando um estudo profundo destas características no processo de aprendizagem da própria cultura.

As experiências que envolvem aliar conteúdo escolar e jogos digitais são traduzidas pelo termo "edutainment" que seria a união de educação e entretenimento. A explicação da utilização destes jogos, é que é mais fácil aprender quando se diverte. Várias pesquisas indicam que isto acontece porque a criança liga o aprendizado às emoções.

O "edutainment" se traduz na oferta de jogos digitais educacionais fornecidos às crianças de uma maneira nova e divertida com conteúdos que seriam ofertados através de livros (EMBI \& HUSSEIN, 2005, p. 28).

Embi \& Hussein (2005) propõem que o "edutainment" seria uma forma em que educadores com expertise em ciências, associados ao desenvolvedor de jogos, criassem um ambiente motivador para que as crianças que têm dificuldade de aprender consigam assimilar os conceitos mais difíceis.

A maioria dos estudantes está exposta a aprendizagem visual das televisões, computadores e jogos desde a mais tenra idade. O uso de multimídia, portanto, é bastante efetivo, já que estes estudantes já estão acostumados com este processo de aprendizagem.

Nesse processo, a utilização da multimídia, que é a combinação de texto conjugado com sons e imagens, está sendo utilizado em universidades, em cursos de sociologia, estatística, administração de empresas e línguas já faz algum tempo (KARAKAYA, AINSCOUGH, CHOPOORIAN, 2001).

Segundo Raph Koster (2013, p. 40) "A diversão dos jogos surge da maestria”. Os jogos são máquinas para produzir interações desafiadoras que geram sentimentos de progresso, competência e maestria movidos pela motivação intrínseca, às alegrias inatas em uma atividade.

Assim como filmes livros, os jogos têm várias formas de designar o público, de acordo com Fisher (2014), incluindo:

- Casual - um jogador que tende a ter tempo limitado para jogar. Os jogos casuais geralmente são projetados para serem jogados em rajadas curtas.

- Núcleo ou midcore - um jogador que gosta de uma ampla gama de jogos, mas que investirá tempo para jogar jogos que exigem um compromisso maior de tempo para serem concluídos.

- Hardcore - um jogador que investe muito tempo e energia no jogo, muitas vezes jogando jogos que exigem dezenas de horas para serem concluídos. Os jogadores hardcore costumam ser considerados os jogadores estereotipados.

Não existe outro meio da pessoa proporcionar em si todos esses fatores. Os livros e filmes talvez sejam quem mais se aproxime disso, apresentam algumas dessas características, porém, não são interativos e, por vezes, são experiências para apenas uma pessoa. Os jogos, no melhor dos casos, são experiências altamente interativas e sociais (PRENSKY, 2012).

\subsection{Jogabilidade a motivação}

A jogabilidade é o que move a motivação e a imersão em um jogo digital. A jogabilidade proporciona uma experiência que é única em cada jogo, as conquistas e desafios deixam seus usuários imersos em um mundo de infinitas possibilidades, interesse e participação.

Para Prensky (2010), “a jogabilidade é um conjunto das ações e estratégias empregadas pelos designers de games para conquistar e manter o jogador envolvido, motivado e completar cada nível e um game inteiro".

$\mathrm{O}$ crescente interesse nos jogos tem feito com que ocorra uma mudança mais profunda na jogabilidade, à motivação. A oferta principal de muitas novas categorias de produtos está facilitando a motivação (pense em saúde, educação, bem-estar, autogestão, sustentabilidade, engajamento dos funcionários). $\mathrm{E}$, 
como a utilidade e a usabilidade são cada vez mais comoditizadas, a experiência, a emoção e a motivação tornaram-se os novos diferenciais de mercado.

Karakaya, Ainscough \& Chopoorian (2001) utilizaram multimídia num curso de marketing para analisar a efetividade da aprendizagem em diferentes tamanhos de classes. A efetividade foi maior na utilização de multimídia neste caso. A multimídia associada à aprendizagem experiencial $\mathrm{e}$ o "edutainment convergem na utilização do que podemos chamar de "serious games"”.

Mas, como podemos definir "serious games"?

Os "serious games" podem ser elaborados para as seguintes áreas: militares, saúde, empresas, governo, educação, política e religião (MICHAEL \& CHEN, 2007, p. 45). Na área militar, temos o America's Army, criado em 2002, que é uma das melhores ferramentas para recrutamento militar. É utilizado por 80 mil candidatos ao serviço militar por ano nos Estados Unidos.

Os "serious games" faturaram US\$ 1,5 bilhões em 2008 (DENBERRRY, 2007, p.1), provando ser um mercado significativo. Eles são utilizados com a intenção de melhorar aspectos de aprendizagem. Os "serious games" são aplicados em treinamento nas áreas de serviços, militares, saúde e principalmente na educação corporativa.

Para Fisher (2014), os jogos sérios são aqueles que têm um benefício de aprendizagem ou pró-social, como simulações de treinamento ou jogos que aumentam a conscientização sobre um tópico, eles são criados para todas as idades, desde crianças a idosos, em uma grande variedade de assuntos, desde educação sexual até treinamento militar.

Os jogos quando desenhados com o objetivo de ensinar apresenta resultados significativos. Como consequência, algumas empresas como Mckinsey e Johnson \& Johnson estão utilizando jogos para melhorar a comunicação entre os gerentes. O próprio McDonalds treina o seu pessoal de atendimento através de jogos (DENBERRY, 2007, p. 9).
Por definição, os jogos educativos para crianças são jogos sérios, mas raramente são referidos como jogos sérios. Em vez disso, eles são referidos como jogos educativos para crianças. Para Prensky (2010), os games são atraentes porque o objetivo principal de seus designers é manter o usuário envolvido.

A expansão do envolvimento ou engajamento, expressão usada nos negócios e governos, dissemina este fenômeno em diversas áreas. A Worcester Polythechnic Institute criou em 2003, o Mass Balance, um jogo na área de governo, simulando o orçamento do estado de Massachussets mostrando as dificuldades de decisão dos governantes e responsáveis pelas políticas públicas.

Lançado pela Nintendo, o Mário Teaching Typing, é um exemplo do uso do game para fins educacionais. As ideias centrais desta reflexão feita por Blikstein (2006), é que o educador deve tomar consciência sobre o funcionamento da mente dos aprendizes, deve-se questionar a existência de uma realidade metafísica e de um conhecimento monolítico sobre ela e que o aprendiz inexiste em isolamento.

Por outro lado, Luckesi (2010) coloca que os professores realizam praticamente três procedimentos sucessivos: medida do aproveitamento escolar, transformação da medida em nota ou conceito e utilização dos resultados identificados.

Não entrando na discussão que ele coloca entre verificação e avaliação, pode-se considerar que estes três procedimentos podem sugerir caminhos num processo de avaliação das disciplinas e, portanto uma base para a avaliação de jogos.

Dentro do contexto avaliação, e já considerando os instrumentos utilizados para tal, Ricardo \& Fonseca (2006), colocam que, entre as opções mais indicadas para o processo de avaliação, são recomendadas a realização de: provas objetivas com questões abertas ou fechadas de múltipla escolha, mapas conceituais que estabelecem as conexões entre os conceitos, exercícios de auto avaliação, onde o discente avalia o quanto aprendeu de certo conceito, portfólio, contendo atividades escritas tipo ensaio, tarefas sugeridas pelo docente, participação nas tarefas de grupo, contribuições em listas e chats, frequência e 


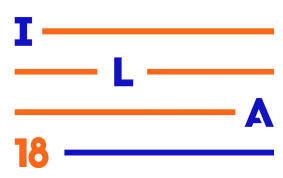

objetivos de contato com o docente, referências consultadas e recursos adicionais oferecidos pelo discente ao grupo.

Já Santos (2006) sugere que para o professor avaliar o processo de aprendizagem, ele precisa coletar e analisar os seguintes aspectos:

- Os caminhos percorridos pelos alunos no material didático fornecido pelo professor, fontes consultadas e frequência das consultas.

- Fontes ou recursos complementares pesquisados fornecidos pelo professor.

- Fontes ou recursos complementares localizados pelos alunos.

- Contribuição dos alunos nas atividades que envolvem cooperação.

- Estilo de trabalho: uso de material fornecido pelo professor versus material complementar.

- Participação nas reuniões de grupo.

- Regularidade dos contados do aluno com o professor.

- Nível de utilização de recursos disponíveis no curso e sua adequada utilização através dos trabalhos e provas realizados.

Dentro do aspecto da concepção do processo ensino aprendizagem, Oliveira, Moreira e Arnold (2006) colocam que devem ser consideradas três concepções, a saber: a concepção empirista que se caracteriza pela ação determinante dos estímulos selecionados pelo professor; a concepção racionalista que se contrapõe à empirista onde se concebe o aprendizado a partir do exercício de estruturas racionais pré-formuladas no aluno e, por fim, a concepção interacionista, que é o processo construtivista do processo ensino aprendizagem que explica que o aluno aprende através da troca que este realiza com o meio.

Para esta construção do conhecimento contribuem dois tipos de experiência: a física, que se apoia nos resultados constatáveis e; a lógico-matemática, que decorre da construção da relação entre os objetos. Prensky (2010) expõem sua perspectiva, de que o estudante passa tanto tempo jogando jogos interativos ricos, divertidos e envolventes que não aceitarão mais um aprendizado penoso e entediante.

Uma questão importante também no processo ensino aprendizagem é o que Cortelazzo (2006) chama de aprendizagem colaborativa, que se constrói na equipe de trabalho, de estudo, de pesquisa e por vontade e consenso dos seus participantes. Esta cooperação é induzida e orientada pelo professor.

No entanto, em seu estudo a participação em ambientes de aprendizagem colaborativos não se apresenta com frequência. Por fim, ao considerar todas as questões acima relacionadas aos jogos digitais, podemos inferir que estas podem se constituir em significativos elementos mediadores que atuam na Zona de Desenvolvimento Proximal ZDP dos sujeitos.

Para Vigotsky (1984) a ZDP caracteriza-se pela necessidade que o sujeito tem da ajuda do outro para realizar atividades que ainda não pode se concretizar de forma independente. Assim, a linguagem midiática tem um papel fundamental nesse processo de mediação.

\section{Resultados e discussão}

Os resultados podem traduzir como aprendizagem ativa, pois está constantemente conhecendo e utilizando o conhecimento dentro e fora do jogo e vai construindo sua expertise.

É perceptível que os alunos acreditam que de fato conseguem aprender por meio dos jogos digitais, é o que Tell (2015) chama de aprendizagem por ação e o que autores como Murakami e Almeida (2014) e Murakami, Leite Júnior e Reinaldo (2013) também verificaram em suas pesquisas.

Os resultados mostram que jogos são capazes de proporcionar um bom ambiente de simulação, sendo percebido pelos alunos como ferramenta pedagógica facilitadora da aprendizagem e sedimentação dos 


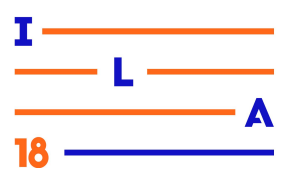

conhecimentos educacionais.

Projetar para as crianças é uma experiência desafiadora, porque está envolvido em criar uma experiência digital para seres humanos que ainda não tem a capacidade cognitiva para entender a abstração e ainda são influenciadas pelos seus pais.

Essa atual geração de crianças denomina-se nativa digital, o que significa que a tecnologia foi e sempre será uma parte de suas vidas, eles acreditam que a tecnologia existe para servi-las. Com isso vêm a tecnologia como uma ferramenta para a expressão, experimentação e comunicação. E projetar para estes pequenos é desafiador.

Segundo a autor Gelman (2011) às necessidades explícitas para fazer uma trajetória divertida, envolvente e gratificante, por que essas crianças ainda estão em fase pré-operacional, mas eles apresentam seus próprios desafios de projeto com base em seu desenvolvimento cognitivo, físico e emocional.

Desenvolver projetos criativos do "mundo real" no virtual, usando padrões de design de interação para orientar a criança em uma experiência que brinquem e aprendam, requer uma sincronia de elementos de design, jogos digitais e desenvolvimento infantil.

Salienta-se, de acordo com o que foi analisado na bibliografia estudada sobre o assunto, a necessidade de incrementação da pesquisa de design, uma vez que é uma área que tem apresentado grande importância no mercado, com o crescimento na área de jogos.

Vislumbrou-se o estabelecimento de diretrizes básicas para criação de interfaces dedicadas às crianças, sendo agrupadas em parâmetros basilares que apontam para o usuário e sua satisfação.

Foi possível observar ainda que o jogo traz interação entre os alunos, sendo rico em simulação da realidade, estimulando sua aprendizagem. O estabelecimento de diretrizes serve de base para a concepção de um jogo, demonstrando maneiras de como modela-las para atender as características desejadas.
Dentro desse contexto, onde a situação histórico-cultural que o mundo atravessa, configura um contexto novo, é preciso não perder de vista a historicidade da existência humana, não se deixando iludir pela ideia de que o fim das utopias iluministas do progresso humano possa significar o fim da história e o fim do trabalho da razão.

É preciso ainda ter presente que o conhecimento continua tendo sua tarefa de intencionalizar a realidade: ele é a única ferramenta de que se dispõem para a construção do sentido da ação individual e coletiva.

Os jogos digitais oferecem um lugar perfeito para crianças, para desafiar o status quo e aprender mais sobre o mundo em torno deles. As crianças precisam se sentir como parte da experiência, e eles precisam ser capazes de observar e compreender as interações dos personagens da experiência, como os jogadores

\section{Referências Bibliográficas}

ALVES, Lynn Rosalina Gama. Videogames algo mais que a violência. In Jogos Eletrônicos:

mapeando novas perspectivas. Florianópolis: Visual Books, 2009.

FISHER, Carla. Designing Games for Children: Developmental, Usability, and Design

Considerations for Making Games for Kids. (Locais do Kindle 211-214). CRC Press. Edição do Kindle.

\section{GEE, James Paul. What video gameshave to teach} us about learning and literacy. New York:

Palgrave Macmilan, 2007.

JENKINS, Henry. Convergence Culture: where old and new media collide. New York, New York University Press, 2006.

JOHNSON, Steven. Surpreendente!: A televisão e o videogame nos tornam mais inteligentes. Rio de Janeiro: Campus, 2005.

KOSTER, Raph. Theory of fun in game design.

Estados Unidos: Paraglyph Press, 2013.

LÖWGREN, Jonas; STOLTERMAN, Erik.

Thoughtful interaction design: A design 


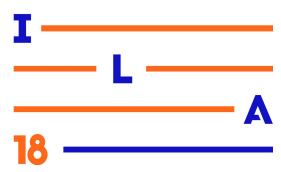

perspective on information technology. Mit Press, 2004.

MATTAR, Fauze Nagib. Pesquisa de marketing. São Paulo: Atlas, 1994

MCGONIGAL, Jane. A realidade em jogo. Rio de Janeiro: Best Seller, 2017.

MENDEZ, Laura; ALONSO, Mercedes; LACASA, Pilar. Buscando nuevas formas de alfabetización: ocio, educación y videojuegos comerciales (mimeo), 2007.

MICHAEL, David, CHEN, Sande. Serious games, games that educate, train and inform. Boston, Ma: Thomson course technology PTR, 2006.

PEREIRA, Filipe, ALVES, Lynn Rosalina Gama. O papel do historiador no desenvolvimento de um game. Rio de Janeiro: SB Games. 2009.

PRENSKY, Marc. Digital Natives, Digital Immigrants -- A New Way to Look At Ourselves and Our Kids.

PRENSKY, Marc. Não me atrapalhe, mãe-Eu estou aprendendo. São Paulo: Phorte, 2010.

SAFFER, Dan. Designing for interaction: creating innovative applications and devices. New Riders, 2010.
SANTAELLA, L ú c i a. Games e comunidades virtuais. D i s p o n í v e 1 e m:

$<$ http://www.canalcontemporaneo.art.br/tecnopolitic as/archives/000334.html $>>$. Acesso em julho de 2018.

SHAFFER, David Williamson. How Computer Games Help Children Learn. Palgrave Macmillan, EUA, 2006.

SPECTOR, P. E. Summated rating scale construction: nan introduction. Iowa: Sage Publications. 1998.

VIGOTSKY, L.S. A formação social da mente. São Paulo: Martins Fontes, 1998.

WARREN, Tom. Design for Kids: Digital Products for Playing and Learning. TECHNICAL

COMMUNICATION, v. 62, n. 3, p. 211-212, 2015.

Agradecimentos

Os agradecimentos ao Pós Design da Universidade Federal de Santa Catarina em possibilitar a realização dessa pesquisa e a CAPES por providenciar recursos financeiros para sua execução. 